\title{
GÉNERO LITERARIO Y REFERENCIA FICCIONAL
}

\author{
LITERARY GENRE AND FICTIONAL REFERENCE
}

\author{
Matías Rebolledo Dujisin \\ Universidad de Chile. Santiago, Chile \\ majorebo@gmail.com
}

\begin{abstract}
Resumen: El objetivo de este artículo es incorporar a la discusión sobre una teoría general de la referencia en la ficción, particularmente en la ficción narrativa literaria, las variables que se presentan en la codificación genérica, como institución social y cultural fundamental para la comunicación literaria concreta. De este modo, primeramente se introduce la problemática general de la referencia en la ficción, para luego presentar las (posibles) variantes que se producen en diferentes géneros, a través del ejemplo (puramente operacional y de ninguna manera acabado) de tres géneros literarios específicos.
\end{abstract}

Palabras clave: Propiedades discursivas, pragmática de la literatura, ficcionalización, referencialidad.

\begin{abstract}
Being the genre the social and cultural institution on which mainly depends the concrete literary communication, this article focuses on the generic codification as a fundamental variable to consider in the general discussion on fictional reference, especially on narrative literature. The first part of the article introduces the general problem of fictional reference, and then it presents the possible variables that emerge from different genres, using as example three specific narrative genres (with no pretension of an accurate definition, but only methodological).
\end{abstract}

Keywords: Discursive properties, literary pragmatics, fictionalizing, referentiality.

Recibido: 16.06.2014. Aceptado: 30.01.2015. 
Considerando que el género es la institución social y literaria que rige (convencionalmente) la comunicación literaria real $^{1}$, y dado que la adscripción a un género provee de un marco referencial (con sus propias normas), tanto para la creación como para la recepción, es lícito preguntarse si, bajo un marco general, estas variables genéricas establecen algún distingo entre clases de textos, tanto en sus maneras de referir cuanto en la interpretación de dicha referencia (los contenidos descriptivos que el lector puede identificar en el acto de referir) por parte de un lector implícito, y qué consecuencias pragmáticas implicaría dicha diferencia, sobre todo en un nivel interpretativo (que va desde lo que el texto implica, a lo que el texto 'quiere decir' en tanto acto de habla; esto es, los contenidos de verdad que de él podrían desprenderse).

Para plantear el problema debo necesariamente introducir un marco general de la cuestión. Asumo aquí algunas propuestas teóricas que serán la base para el desarrollo a presentar. Lo primero que hay que establecer es que el discurso ficcional se conforma en base a un tipo 'especial' de enunciados, que difieren de los enunciados dichos 'en serio' en un contexto real. No se diferencian sustancialmente en la forma, como alguna vez se defendión ${ }^{2}$, pero sí en su fuerza ilocutiva, y en el modo como hay que leer e interpretar dichas proferencias, bajo un marco de presupuestos socialmente establecidos. Esto, como verdad general, no es discutido por los diversos autores que trabajan esta problemática, tanto desde las teorías fregeanas como millianas de la comunicación y la ficción. Lo que sí varía es la explicación (y a veces justificación) de la naturaleza de estos enunciados particulares, que de manera casi intuitiva sabemos, en tanto lectores, leer como lo que son, ficciones ${ }^{3}$.

${ }^{1}$ Género en el sentido propuesto por Genette (1988) en "Géneros, 'tipos', modos", es decir, como "género histórico" (en palabras de Todorov): tipos de discursos literarios concretos, cultural e históricamente codificados, que se presentan en algún momento histórico cultural determinado, para luego desarrollarse, modificarse o desaparecer. En este sentido, opuesto a los "grandes géneros" o modos (narrativo, lírico, dramático), que son más bien posibilidades propias del lenguaje, y no hechos concretos. Cfr. también Todorov (1988) y Martínez Bonati (1983).

${ }^{2}$ Cfr. Jakobson en particular y todo el formalismo ruso en general.

3 Para Searle (1975) la ficción se comprende de actos de habla fingidos que mediante normas asociadas a la ficción suspenden su fuerza ilocutiva real; para Walton 
Uno de los problemas centrales que deben enfrentar los teóricos de la ficción es el central para este artículo: la referencia, esto es, ¿̇cuál es la naturaleza de la referencia en los textos de ficción, qué tipos de referentes presenta, y cómo significan los textos de ficción dados esos referentes (normalmente imaginarios)? En otras palabras, primero, ¿cómo puede significar un enunciado cuyo referente no existe?; segundo, ¿̇cuál es el estatuto dentro de la ficción de los términos, particularmente los nombres, con un referente real? El marco de base para estos problemas utilizado en este texto es la teoría propuesta por Manuel García-Carpintero (2012), que discute diversas teorías de la ficción en general y de la referencia en particular, para presentar una propuesta, que a muy grandes rasgos adopto en este texto.

García-Carpintero parte de la base de que la ficción narrativa se compone de proferencias meramente fingidas, mediante las cuales el hablante fictivo le comunica al lector las proposiciones que tendrían un contenido semántico real en las situaciones imaginarias en que dichas proposiciones se profieren4. Mediante estas proferencias, al lector se le pide (se le invita a) imaginar, con lo que se supone como norma de la ficción que las propuestas deben incitar este acto imaginativo, y que, a la inversa, para que el lector tenga una apreciación adecuada de la ficción debe imaginar a partir de las frases de autor.

En cuanto a la referencia, cabe decir que dentro de la ficción existe una serie de presuposiciones necesarias para que esta se constituya como tal. Entre estas, las presuposiciones referenciales que se ligan a los términos referenciales utilizados en el texto, y que son solo fingidas. El término referencial, en la teoría del autor (a partir de un presupuesto descriptivista), supone una descripción encubierta, que describe la denotación del térmi-

(1990), esta se produce en el marco de una institución social de juegos de fingimiento, en los que mediante un 'atrezo' (props) y principios de generación (las normas del juego) hacen verdaderas atribuciones fictivas; para Schaeffer (2002) la ficción es un fingimiento lúdico compartido -intersubjetivo- (a diferencia del mero engaño), en que el fin lúdico debe ser reconocido por el receptor para que el dispositivo ficcional se ponga en marcha, cuyo fin es crear un universo imaginario e invitar al receptor a sumergirse en dicho universo (no creerlo de verdad); para Martínez Bonati (1983) la obra literaria está compuesta por pseudofrases (que imitan una frase auténtica real), que el lector convierte en una frase auténtica, pero imaginaria (le atribuye un contenido de verdad en el mundo imaginario); etcétera.

${ }^{4}$ Cfr. Félix Martínez Bonati (1983: 125-135). 
no; en una primera instancia, la práctica lingüística asociada a este, y luego, toda la información descriptiva que el texto provee. No son, por lo tanto, términos genuinamente referenciales (incluso aquellos nombres con referente real), sino solo fingidos. De manera certera, se opone con esto a las propuestas que defienden que los nombres dentro de la ficción que poseen un referente real refieren directamente a esos nombres u objetos (teorías millianas). Ni las expresiones con referente puramente imaginario ni las expresiones con un referente real son expresiones genuinamente referenciales; solo fingen referir en el contexto de un discurso ficcional, que por virtud de presuposiciones y convenciones socialmente aceptadas el lector toma como reales en un contexto imaginario. Suponer que los términos sin referente real carezcan de contenido semántico y que por ende no puedan significar, solo expresa un pensamiento contraintuitivo que no da cuenta de lo que en realidad todo lector medio comprende. En términos simples, aquellos referentes existen, solo que en un nivel imaginario, lo que se demuestra ampliamente por la comprensión literaria normal (como que todos podamos hablar del Quijote y nos entendamos). Que los términos con referente refieran directamente al objeto o persona con dicho nombre fuera de la ficción (como frases dichas 'en serio') tampoco se sostiene, puesto que según eso el discurso literario debiera ser una especie de pastiche de frases reales y frases imaginarias, con un límite no muy preciso, y que supondría una compleja relación entre un tipo de frase y otro en el discurso ${ }^{5}$.

Esto es bastante conflictivo, y no se condice realmente con la pragmática de la lectura. Asumir, como hace Searle, que hay frases en los textos literarios dichas 'en serio', y por lo tanto ontológicamente distintas de las frases meramente fingidas implicaría un ejercicio heurístico muy complejo en el más simple de los actos de lectura; supondría un desdoblamiento del hablante (básico) en diversos tipos (existenciales) de hablantes, y no se explicaría cómo podrían convivir en el texto, digamos, Buenos Aires, la ciudad real, con los personajes de Rayuela, puramente imaginarios. "To-

\footnotetext{
5 "Las representaciones ficcionales tienen exactamente la misma clase de referentes que la representación común (...) independiente de su fuente, su modo de acceso o su modo de existencia (...) la existencia o inexistencia de lo que nos representamos no cambia en nada la constitución interna de las representaciones" (Schaeffer, 2002: 136-138).
} 
das las familias felices se parecen..." (el principio de Anna Karenina) no supone, a priori, ningún tipo de verdad, ni una verdad referente al mundo real, ni una frase dicha en serio por el autor de la novela, como supone Searle. Proponer esto implica un salto interpretativo que nos llevaría a asociar directamente al narrador o hablante fictivo con el novelista real (que de repente 'fingiría' no ser él en alguna de sus frases), lo cual está dentro de los errores más elementales de la comprensión literaria. Faulker no 'habla' a través del hermano idiota (quien también dice muchas frases aparentemente 'en serio') en El sonido y la furia, y no puede asumirse como fidedigno a cualquier tipo de narrador. La frase de Tolstoi es una proferencia de su hablante fictivo, para el cual aquella frase tiene un contenido de verdad comprobable en las acciones imaginarias del mundo novelesco. Lo que no obsta para que dicho contenido pueda expresar también un pensamiento del autor real, o que el lector pueda extrapolarla, mediante su conocimiento de mundo y sus creencias, al mundo real. En resumidas cuentas, el proceso de fictivización convierte en ónticamente homogéneas las frases que fingen referir (que el lector convierte en frases con un contenido auténtico pero imaginario) y las que refieren realmente, a riesgo de que la ficción pierda su especificidad (las proferencias fictivas serían un accidente de las proferencias serias) y caer en un razonamiento contraintuitivo (Holmes, por ejemplo, no se 'equivoca' si sigue un camino imposible en el Londres real dentro del relato: es el crítico el que se confunde al pensar que el Londres real sirve de marcador rígido para toda proferencia 'Londres', especialmente la fictiva; negando, así, la posibilidad de la ficción, del pensamiento especulativo, de la metáfora, etc.).

No obstante, considera García-Carpintero, la descripción asociada a un término dentro de las ficciones puede coincidir con la descripción de algo de la realidad (eventualmente con el mismo nombre que el presentado en la ficción), gracias a lo cual agregamos información a la ficción proveniente de la realidad (en la medida en que es compatible con la ficción, es parte de la misma). Es evidente que la referencia real de 'Buenos Aires' no es incompatible con la referencia imaginaria de la misma ciudad. De hecho, de no haber una descripción asociada dentro de la ficción más que su nombre en un contexto determinado (una mera mención), inmediatamente el lector informado llenará esa información restante con su conocimiento de mundo. Pero, a la inversa, si el mismo nombre lleva asociado una descripción 
suficiente en el texto, esta se superpone (en su diferencia) a la del Buenos Aires real ${ }^{6}$.

Esta explicación, considero, satisface las necesidades explicativas de la ficción y su referencia. En este texto pretendo incorporar a esta reflexión algunas variantes al problema de la referencia, a partir de la participación de un código discursivo compartido en la comunicación literaria, que es la institución genérica. Esta propuesta, aún en estado de hipótesis, no modifica sustancialmente lo anteriormente descrito (se basa en ello), pero considera algunas condicionantes, esencialmente pragmáticas (del acto de lectura concreto, y los actos imaginarios asociados a ella), que pueden ser relevantes a la hora de describir la relación entre la ficción y su referente, lo que el lector puede considerar como contenido de verdad, y la relación del mundo de la ficción con el mundo real (como acto de habla indirecto)7.

Algunas consideraciones preliminares para partir. Antes que todo, es necesaria la distinción entre los "grandes géneros" de los llamados géneros históricos. Es a estos últimos a los que aludo en este texto, ya que los prime-

${ }^{6}$ Cfr. Albaladejo (1989). De este mismo modo se explica de manera sencilla por qué, con un conocimiento elemental, puede descubrirse a qué lugar (o persona) se está refiriendo indirectamente en un texto cifrado. Asociamos primeramente la descripción al nombre de la ficción, para luego asociar el contenido descriptivo a un nombre otro fuera de la ficción (esto es válido también, creo, para los espacios simbólicos, asociaciones metafóricas, etc.).

${ }^{7}$ Esta reflexión parte de ideas muy distintas a las de Friend (2011), texto ineludible para la consideración del género en la referencia ficcional, y con quien discrepo en buena parte, $\mathrm{y}$ en lo que me parece aceptable es solo porque se refiere a verdades triviales. Me explico: al proponer a la ficción como un género, asume el concepto 'género' sin más, cuando la historia de la teoría literaria nos ha mostrado que la problemática ha estado en el centro de la discusión teórica, desde Aristóteles en adelante [ver, por ejemplo, García Berrío y Huerta (1992) y Genette (1988)], y es un problema no resuelto. Habría al menos que especificar qué entiende por género, más allá de la trivial noción de 'agrupación lógica de elementos que comparten al menos un rasgo en común'. Segundo, los géneros son géneros de algo (sexual, literario, discursivo, musical, etc.). Lo más cercano en su propuesta sería, a mi juicio, la de género discursivo, lo cual, una vez más, es una verdad trivial: que un texto no ficcional difiera en clase de uno ficcional está en la intuición de cada hablante, y propuesto ya en la Poética de Aristóteles. Por último, no explica las clases de atribuciones que le asigna al género; tal cual está, no veo la diferencia sustancial con, por ejemplo, Searle y sus normas horizontales (el género sería el acuerdo tácito con el autor). 
ros corresponden a posibilidades generales del lenguaje, en general, y de la enunciación literaria en particular, por lo que se encuentran en un nivel demasiado inespecífico ${ }^{8}$. Los géneros históricos (como el cuento policial, el drama pastoril, la novela rosa, etc.), en cambio, corresponden a manifestaciones concretas de textos literarios, que codifican algunas propiedades socialmente aceptadas (o normadas, según el caso) que condicionan la producción, la recepción y la circulación del texto, instalando algunos presupuestos básicos inherentes al género, que los distinguen de otros, y que canalizan una cantidad de información relevante que de otro modo haría incomprensible algunas dimensiones del significado del texto en cuestión. Entiendo el género histórico en su nivel más elemental, siguiendo a Todorov (1981, 1988), como la codificación de propiedades discursivas (como ya se dijo, condicionadas social e históricamente). Aunque incorpora más elementos en su análisis, propone que se puede describir un género a partir de propiedades semánticas, sintácticas y pragmáticas. Como lo que aquí se presenta es solo una propuesta, tomaré como punto de arranque dichas propiedades para describir operativamente un género.

Otra consideración previa es que en este texto tomo algunas definiciones ejemplares que me parecen pertinentes, pero que en ningún caso agotan la discusión sobre los fenómenos tratados; esto es, propongo una definición elemental de género literario, no tratar la problemática. Igualmente, los géneros particulares serán definidos operacionalmente, sin agotar las posibles definiciones, y entendiendo que estas pueden resultar insatisfactorias para una serie de variantes. Vuelvo a señalar, en el estado de la cuestión solo pretendo tratar algunos casos ejemplares para introducir la discusión. Finalmente, dado el extenso número de géneros posibles, y el rol ejemplar y operacional que aquí les atribuyo, únicamente analizaré tres géneros, lo suficientemente amplios como para abarcar un buen número de produccio-

${ }^{8}$ Los grandes géneros (lírica, épica, drama) son 'rebautizados' (en la práctica, recuperando la nomenclatura original aristotélica) por Genette (1988) como modos, en tanto, según el autor, corresponden precisamente a modos de la enunciación verbal, y por lo tanto pertenecientes más al ámbito del lenguaje en general (de la antropología lingüística, para ser más exacto) que de la literatura en particular. Para Martínez Bonati (1983) suponen la predominancia de una de las dimensiones semánticas (expresiva, representativa y apelativa), siempre presentes en todo acto comunicativo, y por lo mismo, en la frase imaginaria también. 
nes literarias, y que sirven para contrastar entre ellos. Estos son la ciencia ficción, la novela histórica y el género fantástico.

Como vimos más arriba, en la propuesta de García-Carpintero, la contribución de $\mathrm{n}$ (nombre) es, primariamente, la persona (o ciudad, lugar, etc.) llamada n en la ficción, y secundariamente el conjunto de información descriptiva que la ficción asocia con el nombre. Vimos anteriormente, también, que esa información descriptiva puede estar indirectamente asociada a nombres u objetos de la realidad. Es ese vínculo (y su consecuencia para la comprensión y lectura de textos literarios) el que me interesa trabajar acá.

La ciencia ficción ${ }^{9}$ (CF). Según la propuesta de Vaisman, la CF se diferencia de, por ejemplo, la fantasía espacial, en que esta solo adopta un cierto tipo de contenido o espacio (naves espaciales, artefactos prodigiosos, fechamiento futurista), vinculados a, pero no definitorios de la CF. En cambio, la CF exige la presentación de un mundo posible, partiendo de los datos empíricos (al menos de un saber común) de nuestra época actual, que sirvan de base para que a partir del desarrollo tecnológico y científico se sostenga dicho futuro como una posibilidad verosímil. Así, lo que caracteriza la $\mathrm{CF}$ desde el punto de vista semántico no son los rasgos secundarios antes mencionados, sino la presencia de algún (o algunos) hecho científico que origina y permite el desarrollo del relato (a diferencia, entonces, de la fantasía o la space opera). A su vez, esta exigencia de contenido se condiciona por otra de orden pragmático: no contrariar la aceptabilidad científica vigente al momento de producción del relato (el efecto de realidad que se asocia al sema 'ciencia' de la CF); finalmente, una de orden sintáctico, que es que dichos hechos científicos sean la base de algún cambio importante en el sistema de coordenadas (físicas, sociales, políticas, biológicas) del mundo real que sirve de referente.

${ }^{9}$ Debo la información aquí utilizada al excelente artículo de Luis Vaisman (1986), "En torno a la ciencia ficción: propuesta para la descripción de un género histórico". Lo que expongo no es más que una paráfrasis de su propuesta. 
La anterior descripción (que deja fuera fantasías generalmente incorporadas a la CF como "La guerra de las galaxias" o novelas futuristas pero no científicas, como las de Verne) supone, por lo tanto, una vinculación importante por parte del receptor entre el discurso fictivo y el mundo real. Cuando el narrador de 1984 refiere a 'Londres', no existe, como algunos quisieron ver, la referencia al Londres real (al menos el de 1949). Es un Londres (capital de 'Oceanía') que en nada se asemeja (la descripción asociada al nombre no coincide) al Londres real. Sin embargo, evidentemente no es un alcance onomástico (como sería que en 1949 un lector de la novela se llamase efectivamente Winston Smith). Si seguimos la definición antes dada, el lector de 1984, si quiere leer correctamente la novela, debe entender que el Londres de la novela necesita asociarse al Londres real, como un mundo posible, futuro, necesariamente verosímil. Esto es, el narrador presenta un mundo, a través del cual indirectamente el autor real profiere algo así como 'considerando la situación (política, tecnológica) actual del mundo, es verosímil pensar que de continuar de este modo, y si ocurre tal y tal evento, un futuro (mundo) posible es el que se presenta en la novela; particularmente, bajo los mismos criterios, Londres podría llegar a ser (es verosímil pensarlo) una ciudad como la presentada en la novela'10. Lo mismo ocurre con, por ejemplo, HAL 9000 en "2001: Odisea del espacio”, que no existe en 1969, pero dado el desarrollo tecnológico y particularmente computacional, es verosímil pensar que podría existir.

Para sintetizar, la CF, para ser tal, exige tanto desde la intención autorial cuanto en la pretendida recepción, no presentar una referencia hacia ningún (o casi ningún ${ }^{11}$ ) hecho o nombre del mundo real, o cuya descripción asociada se puede asimilar directamente al mismo; sin embargo, por contraparte, exige al menos una referencia indirecta a algún(os) hecho(s) o nombre(s) identificables, por el lector, en el mundo real, como descripción (posible) de un estado futuro de esos nombres o hechos. De este modo

${ }^{10}$ Por eso, muchas veces la $\mathrm{CF}$ es referida como literatura 'especulativa', dado que, podríamos decir, ficcionaliza un razonamiento deductivo (serio) que nos lleva de la situación actual a posibilidades de futuro. El mismo Orwell negaba haber escrito CF, así muchos autores, dado el sesgo de 'literatura de masas' que carga su nombre genérico.

${ }^{11}$ Estoy obviando algunas presuposiciones obvias, particularmente las que se desprenden del uso mismo del lenguaje. 
la $\mathrm{CF}$ refiere indirectamente al estado actual de cosas, y en la medida en que el hecho científico descrito se establece como causal de una serie de cambios, la causalidad lógico-científica debe estar en la base del desarrollo del mundo posible presentado, y se asemeja, entonces, al pensamiento especulativo, con una estructura (indirecta) más o menos así: 'sobre la base de los datos actuales y dado tal hecho específico, es verosímil pensar que eventualmente los hechos se desarrollarán de tal modo'. Finalmente, la CF requiere la asociación indirecta a los datos del mundo, y presenta como contenido de verdad un potencial mundo futuro.

IV

Novela histórica (NH): Tal vez puede inferirse de lo descrito anteriormente que las propiedades que distinguen a la $\mathrm{CF}$ a grandes rasgos son válidas también para la NH. Es, en un sentido algo basto, el perfecto anverso de la CF (a partir de los datos empíricos del presente se construye verosímil y causalmente un futuro posible, que modifica en alguna medida el referente original -el mundo presente-; a la inversa, la novela histórica parte de los datos empíricos que se poseen en el tiempo actual para construir verosímil y causalmente un pasado posible, que modifica en alguna medida el referente original -el mundo pasado). Por lo mismo, las formulaciones de los (supuestos) actos de habla indirectos implicados por el autor son más o menos equivalentes.

Tomando como base el estudio de Jitrik (1995) considero la NH como un relato que refiere siempre a una realidad anterior (recurriendo a fuentes historiográficas), en general lo bastante alejada del momento de enunciación como para considerarse propiamente histórica y deslindarse de géneros afines, como las memorias. Pero la historia no es un simple depósito, puesto que en el desarrollo del relato necesariamente se va modificando, en mayor o menor medida, el referente original (la descripción a él atribuida). La NH, por lo tanto, reinterpreta la historia y la cultura en general, y tiene como base (su fundamento, su razón de ser) la racionalidad histórica, a la que se le atribuye un cierto contenido de verdad. Así, sustentándose en una 
cierta lógica (histórica), las obras de este género buscan no solo mostrar sino explicar una realidad ${ }^{12}$.

Esto nos permite ya definir el género según las propiedades propuestas, y ver sus consecuencias. Primero, como tema (rasgo semántico), la NH presenta algún(os) hecho(s) del pasado factual, y protagonizado a su vez por personajes que aluden a personas históricas reales (a su vez, estos interactúan necesariamente con personajes puramente ficcionales), sustentado por datos empíricos (fuentes historiográficas, diferenciándolo de la mera fantasía histórica, ambientada en un espacio anterior, pero que no guarda relación con el pasado empírico real: las novelas de Dumas o muchas novelas juveniles actuales). Pragmáticamente supone generar la creencia en el lector de que lo que allí se cuenta pudo haber sucedido en la realidad tal como allí se describe, bajo la lógica histórica (de ahí suponiendo algún grado de verdad); de lo que se desprende también el rasgo sintáctico que exige que el contenido deba, por una parte, articularse lógico-causalmente (no necesariamente de manera cronológica), y que dicho contenido tenga que entenderse como una reinterpretación o modificación del conocimiento de mundo asociado a ese pasado histórico.

No creo que deba extenderme más en este punto ya que, como señalé, la relación del contenido (y particularmente de los nombres) con aquello a lo que refiere en la $\mathrm{NH}$ puede expresarse de manera análoga a la de la $\mathrm{CF}$. La incorporación de elementos ficticios (lo que la distingue de la crónica o textos historiográficos propiamente tales), que define al género, no obsta para asociar el contenido relatado, en tanto mundo posible, con un cierto nivel de verdad. Vale decir, sin perder su carácter ficcional, puede leerse,

${ }^{12}$ Existe una amplia producción novelística contemporánea, particularmente latinoamericana, que reformula el concepto general de $\mathrm{NH}$, normalmente conocida con el nombre de 'nueva novela histórica'. Según Menton (1993), se caracteriza, entre otras cosas, por la subordinación de la representación mimética a ideas filosóficas, por la distorsión consciente de la historia, por la intención metaficcional, la profusa intertextualidad y el espíritu carnavalesco y paródico. Prefiero mantenerme, por el sentido operacional antes señalado, en la definición más tradicional de novela histórica (pese a que la propuesta de Jitrik permite la incorporación de este tipo de novelas, puesto que considera que junto con la referencia al pasado, la NH se va modificando según las nuevas exigencias novelísticas; claramente postmodernas las de la N-NH). 
supongamos, El puente de Alcántara para, entre otras cosas, entender el modo de vida, la estructura social y los procesos históricos en la España medieval, por mucho que los tres personajes protagónicos sean puramente ficticios. O podemos incluso suponer que todos los acontecimientos de Las memorias de Adriano están referidos 'en serio', pero indirectamente, en un texto de ficción, donde es Adriano quien habla ${ }^{13}$.

Como nota para cerrar estos dos géneros, es importante hacer notar que este rasgo pragmático asociado a estos dos géneros por igual, que precisamente se ven determinados por el problema de la referencia, es antes que nada una marca general de las ficciones realistas, en un sentido lato ${ }^{14}$. Ese realismo, que supone, grosso modo, hacer una ficción que 'retrate la realidad tal cual es' -crear un efecto de realidad- es lo que hace que necesariamente muchas ficciones pretendan, aunque sea de manera indirecta, referir (asociar descripciones a los referentes) a personas, lugares, hechos, que pertenecen al mundo externo a la ficción.

Género fantástico: Como contrapunto evidente a los géneros anteriores presento brevemente el género fantástico, basándome de manera general en el texto de Todorov Introducción a la literatura fantástica.

${ }_{13}$ 'En la Ficción MA se hace fictivo que Adriano pensó, dijo, etc., tal cosa'. Pero, a su vez, la autora se encarga de revelar sus fuentes, como para remarcar que este, además de un discurso ficcional, es un discurso que porta un cierto contenido de verdad. Ficcionalizado y especulativo, pero tan especulativo como puede ser el razonamiento histórico, que intenta presentar, bajo los datos empíricos que se manejan, un mundo (posible) pasado, lo más verosímilmente constituido, bajo esta misma lógica.

${ }^{14}$ Lo que lleva necesariamente también una fuerte carga ética. Hay un compromiso tácito (muchas veces) con aquello que dice (de ahí que puedan leerse como verdades autoriales los enunciados del narrador de Tolstoi, como vimos más arriba). La NH supone un compromiso de verdad con aquello a lo que refiere ("In part, certain fictional genres are defined by the nonfictional commitments involved in the work of fiction"; Searle, 1975: 331). De ahí también que pueda leerse, por poner un ejemplo, una película como Apocalypto, que intenta reproducir verosímilmente incluso el habla del mundo maya, solo que todo lo que caracteriza al mundo presentado corresponde a la cultura azteca. Conociendo al autor de la ficción, el compromiso ético lo leo así: 'los indígenas al sur del Río Grande son todos más o menos lo mismo’. 
En una primera instancia pareciera definirse el género por una clausura inmediata de la lógica del mundo real, y por lo tanto que el texto fantástico crea su propia verdad, sin relación (referencial) alguna con el mundo real, o bien, con referencias indirectas, pero muy esporádicas (códigos y referencias culturales, por ejemplo), y débiles (no como la relación que sostiene un nombre propio con su referente real). Sin embargo, en la propuesta de Todorov esto correspondería a lo maravilloso, género vecino pero que se ubica más allá de lo fantástico. Así resume la idea de lo fantástico el autor:

En un mundo que es el nuestro, el que conocemos, sin diablos, sílfides, ni vampiros se produce un acontecimiento imposible de explicar por las leyes de ese mismo mundo familiar. El que percibe el acontecimiento debe optar por una de las dos soluciones posibles: o bien se trata de una ilusión de los sentidos, de un producto de imaginación, y las leyes del mundo siguen siendo lo que son, o bien el acontecimiento se produjo realmente, es parte integrante de la realidad, y entonces esta realidad está regida por leyes que desconocemos (19).

Vale el ejemplo de buena parte de la literatura de Borges o Cortázar, como en "Continuidad de los parques", donde lo fantástico emana de lo que Genette (1989) llamaría metalepsis ${ }^{15}$ : o bien los personajes 'salen' de la novela, reduplicando su historia en el mundo real, o bien lo expresado por el texto coincide punto por punto con la 'realidad' (el primer nivel de realidad) en la ficción. Para que sea fantástica, debe haber al menos un nivel que funcione de manera análoga a la lógica de lo real. Así en el cuento "Autopista del sur", también de Cortázar, donde los famosos embotellamientos a la entrada de París se convierten en uno de dimensiones imposibles (fantásticas), como si hubiese transcurrido un año (las estaciones se suceden) o más en él.

De este modo, lo fantástico se define ${ }^{16}$, en primera instancia, por la necesidad de que el lector perciba en el texto una lógica cercana a lo real, y que deba vacilar, en relación con la aparición sobrenatural, entre la expli-

${ }^{15}$ La irrupción de un nivel narrativo (el de la metadiégesis) en otro (diégesis), ontológicamente separados, sin una razón que lo justifique: los personajes de la 'ficción novelesca' matan al lector de ella.

${ }^{16}$ Aquí tomo los criterios de Todorov, pero los reformulo considerablemente. 
cación 'alucinatoria' (tendencia hacia el realismo) y la de una lógica que escapa de nuestra racionalidad, la propiamente fantástica (ejemplar en este sentido es Otra vuelta de tuerca, de Henry James, que explora estas dos posibilidades, dejando la interpretación absolutamente abierta). Como contenido, esta es una determinación semántica. Pero inmediatamente se anuncia la pragmática: la necesaria vacilación interpretativa del lector, que puede o no identificarse con la del personaje; además, se exige una lectura que debe alejarse de la alegórica o poética, que transforman lo fantástico en otra cosa. En cuanto a lo sintáctico, supone una estructuración lógicoracional del mundo del relato, donde se produce la irrupción de un elemento maravilloso o sobrenatural; del mismo modo, la presencia de elementos fantásticos permite una organización particularmente ceñida de la intriga, manteniendo siempre el suspenso.

Con esto es posible ver que el género fantástico exige una estructuración de mundo posible similar, hasta cierto límite (justamente aquel que define el género), a la de los géneros anteriores. Sin embargo, aunque sea de manera tautológica, una de las funciones del género fantástico es precisamente develar y describir dicho universo fantástico, que por sus propias características no tiene una realidad exterior a la de la ficción (diría aun más: al lenguaje): la descripción y lo descrito no tienen una naturaleza diferente. En términos proposicionales, diríamos que en "Autopista del sur" la contribución de 'París' es, primariamente, la ciudad 'París' en el cuento, y secundariamente el conjunto de información descriptiva que el mismo asocia con el nombre. Esa información descriptiva incluye la que conocemos del París real (a menos que en el cuento se verificara lo contrario). (La propuesta que sigue es algo forzada, ya que no corresponde con un nombre propio, y por lo tanto posee un contenido mucho más flexible). En el mismo cuento, el embotellamiento 'maravilloso' supone un conjunto de información descriptiva del mismo cuento (y solo del cuento), dentro de la cual se puede inferir su necesaria no coincidencia con un embotellamiento (tipo) del mundo real.

Así, para finalizar, considero que en el género fantástico habría un tipo de referencia directa común a toda ficción, explicada más arriba, pero necesariamente un doble tipo, opuesto, de referencia indirecta, según la clase de información asociada. En virtud de esta condición es que el género fantástico puede aun proponer verdades sobre el mundo real (digamos, sobre 
la naturaleza de las ficciones en "Continuidad..."; sobre el tipo de relaciones humanas en el microcosmos de “Autopista...”).

En la idea de género literario se concentran gran parte de las propiedades que caracterizan los distintos tipos de textos literarios y condicionan las expectativas de lectura, y por ende la interpretación de los mismos. No todos los textos se leen igual (no invitan a los mismos actos imaginativos), y esto viene en gran medida prefijado por la convención social que significa el género. Cuando Searle (1975), por ejemplo, propone las normas "horizontales" que dejan en suspenso la aplicación normal de las normas "verticales" (posibilitando ilocuciones fingidas), y cuando señala que "the author will establish with the reader a set of under-standings about how far the horizontal conventions of fiction break the vertical connections of serious speech" (331), no queda muy claro de dónde surgen las normas y cómo establece el lector el entendimiento con el autor. Pues bien, visto desde este punto de vista, los presupuestos genéricos no satisfacen, pero sí fijan de mejor manera algunas de estas posibles normas. Algo similar puede decirse de la teoría del 'hacer-como-que' de Walton (haciendo las salvedades del caso: la teoría de la referencia aquí propuesta difiere sustancialmente con la de este autor; pero no tanto en la teoría general de la ficción), puesto que el código genérico forma parte necesariamente de los principios de generación.

Al menos podemos concordar con Lewis (1983: 274), cuando muestra que la verdad en la ficción surge de la unión entre lo explícitamente dicho por el texto junto a nuestro conocimiento o creencias sobre el mundo, y que hay una tercera fuente a considerar: la intraficcional y la interficcional. Esta última se corresponde plenamente con la idea de género. Resulta que muchas veces un texto es incomprensible, a menos que se esté en conocimiento del código genérico que permite interpretar correctamente lo dicho. Se vincula así lo dicho por el texto, su relación con el mundo real y con otros textos.

Por último, no está demás señalar que esta propuesta se centró solo en tres géneros, y únicamente literarios, pero solo a modo de ejemplo válido 
para cualquier género y, más aun, extensible a otras artes (con sus propias codificaciones genéricas). Particularmente el cine clásico ha establecido una serie de géneros muchos más rígidos y estables que los literarios, y que de todas maneras explican en gran medida lo que el filme 'quiere decir'.

\section{Referencias}

Albaladejo M., T. (1989). La semántica extensional en el análisis del texto narrativo. En G. Reyes (ed.), Teorías literarias en la actualidad (pp. 185-201). Madrid: El Arquero.

Friend, S. (2011). Fictive Utterance and Imaging II. En Aristotelian Society Supplementary Volume, 85, 163-180. New Jersey: John Wiley \& Sons.

García Berrío, A. y Huerta Calvo, J. (1992). Los géneros literarios: Sistema e historia. Madrid: Cátedra.

García-Carpintero, M. (2012). Referencia y ficción. En D. Pérez Chico (coord.), Perspectivas en la filosofía del lenguaje (pp. 307-354). Zaragoza: Prensas de la Universidad de Zaragoza.

Genette, G. (1988 [1977]). Géneros, 'tipos', modos. En M. Garrido Gallardo (comp.), Teoría de los géneros (pp. 183-233). Madrid: Arco / Libros. . (1989 [1972]). Figuras III. Barcelona: Lumen.

Jitrik, N. (1995). Historia e imaginación literaria: Las posibilidades de un género. Buenos Aires: Editorial Biblos.

Lewis, D. (1983). Philosophical Papers. Vol. I. Oxford: Oxford University Press.

Martínez Bonati, F. (1983 [1960]). La estructura de la obra literaria. Barcelona: Ariel.

Menton, S. (1993). La nueva novela histórica de la América Latina. México D.F.: Fondo de Cultura Económica.

Schaeffer, J-M. (2002 [1999]). ¿Por qué la ficción? Toledo: Lengua de Trapo.

Searle, J. (1975). The logical status of fictional discourse. New Literary History, 6, 319-332.

Todorov, T. (1981 [1970]). Introducción a la literatura fantástica. México D.F.: Premia.

. (1988). El origen de los géneros literarios. En M. Garrido Gallardo (comp.), Teoría de los géneros (pp. 31-48). Madrid: Arco / Libros.

Vaisman, L. (1986). En torno a la ciencia ficción: propuesta para la descripción de un género histórico. Revista Chilena de Literatura, 25, 5-27.

Walton, K. L. (1990). Mimesis as make-believe: On the foundations of the representational arts. Cambridge: Harvard University Press. 